Document downloaded from:

http://hdl.handle.net/10251/101444

This paper must be cited as:

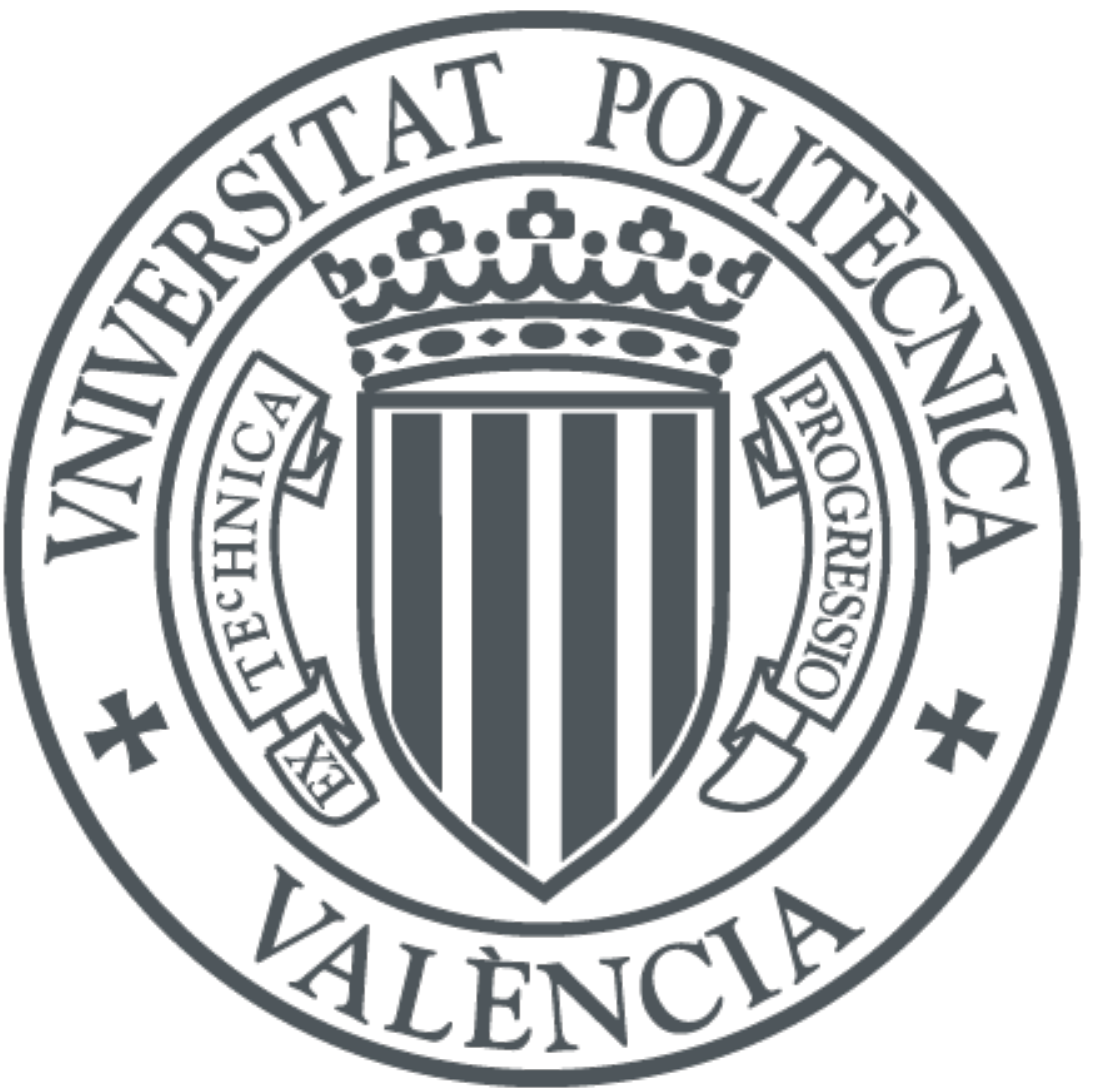

The final publication is available at

http://doi.org/10.1039/C4TA02521K

Copyright The Royal Society of Chemistry

Additional Information 


\section{Porous Macromolecular Dihydropyridyl Frameworks Exhibiting Catalytic and Halochromic Activity}

Bo Xiao, ${ }^{\mathrm{a}, \mathrm{b}}$ Timothy L. Easun, ${ }^{\mathrm{a}}$ Amarajothi Dhakshinamoorthy, ${ }^{\mathrm{c}, \mathrm{g}}$ Izabela Cebula, ${ }^{\mathrm{d}, \mathrm{e}}$ Peter H. Beton, ${ }^{\mathrm{d}}$ Jeremy J. Titman, ${ }^{\mathrm{a}}$ Hermenegildo Garcia, ${ }^{\mathrm{c}}$ K. Mark Thomas ${ }^{\mathrm{f}}$ and Martin Schröder ${ }^{*}$,a

${ }^{a}$ School of Chemistry, University Park, University of Nottingham, Nottingham NG7 2RD, United Kingdom. Fax: +44 (0)115 9513563; Tel: +44 (0)115 9513490; E-mail: m.schroder@nottingham.ac.uk

${ }^{b}$ School of Chemistry \& Chemical Engineering, Queen's University Belfast, David Keir Building, Stranmillis Road, Belfast BT9 5AG, United Kingdom.

${ }^{c}$ Instituto de Tecnología Química (CSIC-UPV), Avda. de los Naranjos s/n., 46022 Valencia, Spain.

${ }^{d}$ School of Physics and Astronomy University Park, University of Nottingham, Nottingham NG7 2RD, United Kingdom.

${ }^{e}$ Institute of Experimental Physics, University of Wroclaw, pl. M. Borna 9, 50-204 Wroclaw, Poland.

${ }^{f}$ Wolfson Northern Carbon Reduction Laboratories, School of Chemical Engineering and Advanced Materials, Newcastle University, Newcastle upon Tyne NE1 7RU, United Kingdom.

${ }^{g}$ Centre for Green Chemistry Processes, School of Chemistry, Madurai Kamaraj University, Tamil Nadu, India 625021.

Keywords: organic polymer, catalysis, dihydropyridyl, halochromic, Knoevenagel condensation, porosity, gas adsorption. 


\section{Abstract}

New porous macromolecular frameworks (PMFs) have been designed and prepared by the condensation of dialdehydes with aminoacrylonitriles. Two porous materials were prepared by reacting 3,3'-benzene-1,4-diylbis(3-aminoprop-2-enenitrile) with benzene-1,4dicarbaldehyde and biphenyl-4,4'-dicarbaldehyde to give PMF-NOTT-1 and PMF-NOTT-2, respectively. Adsorption and desorption studies of $\mathrm{N}_{2}(77 \mathrm{~K})$ and $\mathrm{CO}_{2}(273-303 \mathrm{~K}$ and 20 bar) were used to characterize the porosity of these materials. $\mathrm{CO}_{2}$ adsorption measurements indicate that these PMFs have similar porosity with Dubinin-Radushkevich micropore volumes of 0.142 and $0.144 \mathrm{~cm}^{3} \mathrm{~g}^{-1}$ and uptakes of 28.4 and $28.9 \mathrm{wt} \%$ at $20 \mathrm{bar}, 273 \mathrm{~K}$ for PMF-NOTT-1 and PMF-NOTT-2, respectively. The isosteric heats of adsorption for $\mathrm{CO}_{2}$ at zero surface coverage were $31.9 \mathrm{~kJ} \mathrm{~mol}^{-1}$ (for PMF-NOTT-1) and $33.1 \mathrm{~kJ} \mathrm{~mol}^{-1}$ (for PMFNOTT-2). However, $\mathrm{N}_{2}$ adsorption studies at $77 \mathrm{~K}$ indicated that PMF-NOTT-2 shows activated diffusion effects due to the presence of some narrow ultramicroporosity. The conjugated systems of these frameworks can be reversibly switched by varying proton concentration in solution and these materials thus demonstrate halochromic properties. PMFNOTT-1 constructed from shorter building blocks than PMF-NOTT-2 exhibits higher catalytic activity and selectivity in Knoevenagel condensation reactions of maleonitrile with benzaldehydes. The advantages of using PMFs as catalysts or adsorbents are their excellent thermal and chemical stabilities and they can be recovered and regenerated for re-use. 


\section{Introduction}

Porous materials fabricated by the assembly of molecular building units have been extensively investigated, especially for applications for gas storage and capture, and catalysis. $^{1-11}$ Such materials need to show both chemical and physical stability since degradation of porous structures reduces their activity and results in low efficiency and poor economics for material utilization. Considerable efforts have focused on developing strategies to prepare organic framework materials showing high chemical stability and permanent porosity. ${ }^{12-16}$ Diverse and distinct chemical functionalities such as catalytically active $\mathrm{N}$-heterocyclic moieties can be incorporated into these materials to formulate catalytic or optoelectronic properties. ${ }^{17,18}$ In previous work, we have confirmed the construction of a supramolecular organic frameworks (SOF) via condensation of aminoacrylonitrile with terephthalaldehyde to produce 1,4-bis(4-(3,5-dicyano-2,6-dipyridyl)dihydropyridyl) benzene (3 in Scheme 1). ${ }^{19}$ This material packs in the solid state to afford a stable three dimensional framework held together via hydrogen bonds and $\pi$ - $\pi$ stacking interactions. The framework shows permanent porosity and effective gas storage properties.

We report herein a "bottom up" strategy based upon the condensation of 1,4phenylaminoacrylonitrile 4 with 1,4-phenyldialdehydes 5 to generate porous macromolecular frameworks (PMFs) 6, denoted as PMF-NOTT-n $(n=1$ or 2$)$ (Scheme 1). These porous macromolecular frameworks contain dihydropyridine groups, which can be protonated, and this exerts a significant impact on electron delocalization in these amine-functionalized conjugated systems thereby imparting halochromism to the porous polymer. In this study we show that the halochromism can be used to follow the course of catalytic Knoevenagel condensation reactions of maleonitrile with benzaldehydes. 


\section{Experimental}

\section{Synthesis of porous macromolecular frameworks (PMFs)}

\section{Synthesis of 3,3'-benzene-1,4-diylbis(3-aminoprop-2-enenitrile).}

In a typical synthesis, 1,4-dicyanobenzene $(2.6 \mathrm{~g}, 20 \mathrm{mmol})$ was mixed with acetonitrile $(\mathrm{MeCN})(3.3 \mathrm{~g}, 80 \mathrm{mmol})$ in benzene $(200 \mathrm{~mL})$ until all solids were dissolved. Potassium tbutoxide (13.5 g, $120 \mathrm{mmol}$ ) was added to the solution to form an orange suspension, which was stirred continuously at ambient temperature for $48 \mathrm{~h}$. An aqueous saturated solution of $\mathrm{NaHCO}_{3}(500 \mathrm{~mL})$ was added and the orange solid was collected and dissolved in hot DMF (100 mL). The solution was concentrated by rotary evaporation to remove $\sim 80 \%$ of the DMF, and $\mathrm{CH}_{3} \mathrm{OH} /$ water $(300 \mathrm{~mL} ; 1: 5(\mathrm{v} / \mathrm{v}))$ was added to give a white precipitate. The white solid product was collected and dried under vacuum. Product yield was 50-70\%. IR (ATR) $v=$ $3438,3333,3244,2188,1637,1578,1513,1422,1292,853,794,695,607 \mathrm{~cm}^{-1}$ (see Figure S2); ${ }^{1} \mathrm{H}-\mathrm{NMR}\left(\mathrm{DMSO}_{-} \mathrm{d}_{6}\right): 7.64(s, 4 \mathrm{H}, \mathrm{H}-\mathrm{Ar}), 6.88\left(s, 4 \mathrm{H},-\mathrm{NH}_{2}\right), 4.27 \mathrm{ppm}(s, 2 \mathrm{H},=\mathrm{CH}-\mathrm{CN})$ (see Figure S1).

\section{Syntheses of PMF-NOTT-1 and PMF-NOTT-2}

The 3,3'-benzene-1,4-diylbis(3-aminoprop-2-enenitrile) $(1.26 \mathrm{~g}, 6.0 \mathrm{mmol})$ was mixed with aldehyde benzene-1,4-dicarbaldehyde $(0.40 \mathrm{~g}, 3.0 \mathrm{mmol})$ or biphenyl-4,4'-dicarbaldehyde $(0.63 \mathrm{~g}, 3.0 \mathrm{mmol})$ in acetic acid $(50 \mathrm{~mL})$. The solution was refluxed at $120^{\circ} \mathrm{C}$ for $24 \mathrm{~h}$ until a yellow precipitate was formed. The hot suspension was filtered, and the yellow solid product collected, washed thoroughly with water until the $\mathrm{pH}$ of the washings was $\sim 7.0$. The yellow product was washed with $\mathrm{MeOH}$ via Soxhlet extraction to remove residual impurities and the material was dried in vacuo to give the PMFs in about $65 \%$ yield. Analytical Data: for PMFNOTT- $1\left(\mathrm{C}_{16} \mathrm{H}_{8} \mathrm{~N}_{3}\right)$ Calculated: C 79.3, H 3.3, N 17.3\%; Found: C 81.2, H 3.2, N 15.6\%; for PMF-NOTT-2 $\left(\mathrm{C}_{19} \mathrm{H}_{10} \mathrm{~N}_{3}\right)$ Calculated: C 81.4, H 3.6, N 15.0\%; Found: C 83.3, H 3.5, N $13.2 \%$ 


\section{Stability tests}

PMF-NOTT-1 and PMF-NOTT-2 were tested in the following solvents: $n$-hexane, toluene, $\mathrm{CH}_{2} \mathrm{Cl}_{2}$, tetrahydrofuran (THF), $\mathrm{CHCl}_{3}$, ethyl acetate, methanol, $\mathrm{MeCN}$, dimethylformamide (DMF) and dimethyl sulfoxide (DMSO). Tests were carried out at ambient temperature and the samples were placed in solvents for two weeks. The yellow PMFs did not dissolve as confirmed by ${ }^{1} \mathrm{H}$ NMR spectroscopy of the $\mathrm{CDCl}_{3}$ or DMSO-d $\mathrm{d}_{6}$ solvents. The PMFs did not dissolve in acids $\left(\mathrm{H}_{2} \mathrm{SO}_{4}, \mathrm{HNO}_{3}\right.$ and $\left.\mathrm{HCl}, 2-6 \mathrm{M}\right)$ at room temperature, or in bases $(\mathrm{NaOH}$ and $\mathrm{KOH}, 2-6 \mathrm{M})$. In basic solution, they changed from yellow color (protonated form) to red (deprotonated form). The red deprotonated PMFs can be protonated to the yellow form by water or acids.

\section{Characterization of PMF materials}

\section{Infrared spectroscopy}

Thermo Scientific Nicolet iS5 with iD 5 Diamond Advanced ATR was used to collect IR spectra of powder samples, with 16 scans per spectrum and a resolution of $4 \mathrm{~cm}^{-1}$.

\section{Thermogravimetric analysis (TGA)}

Thermogravimetric analysis was conducted using a PerkinElmer Pyris 1 TGA analyser. The weight loss profiles of samples with increasing temperature were obtained at a heating rate of $3 \mathrm{~K} \mathrm{~min}^{-1}$ under a flow of $\mathrm{N}_{2}$.

\section{Solid-state NMR}

${ }^{13} \mathrm{C}$ CPMAS spectra were recorded using a Bruker Advance III spectrometer operating at a ${ }^{13} \mathrm{C}$ Larmor frequency of $150.9 \mathrm{MHz}$ and equipped with a triple-resonance $2.5 \mathrm{~mm}$ MAS probe. Cross polarization was achieved using a ramped ${ }^{1} \mathrm{H}$ contact pulse and decoupling using the SPINAL64 sequence with a radio frequency field of $100 \mathrm{kHz}$. The MAS rate was $17 \mathrm{kHz}$, the contact time was $2 \mathrm{~ms}$, the relaxation delay was $2 \mathrm{~s}$, and 20000 scans were acquired. Chemical shifts were referenced externally to TMS using adamantane as a 
secondary reference. Assignments were made with the help of the ${ }^{13} \mathrm{C}$ structure prediction package available as part of the MarvinSketch software (ChemAxon Ltd.)

\section{$U V$-Vis spectra}

Solid-state UV/Vis spectra were recorded using an Ocean Optics USB2000+UV-VIS-ES spectrometer equipped with a DT-MINI-2-GS light source and an R400-7-UV-VIS fiberoptic reflection/backscattering probe. Spectra were recorded using Spectrasuite software, averaging 10 scans with an accumulation time of $500 \mathrm{~s} / \mathrm{scan}$.

\section{Adsorption Studies}

A Hiden Intelligent Gravimetric Analyser (IGA) was used to measure $\mathrm{CO}_{2}$ adsorption isotherms. The IGA is a fully computer controlled microbalance in an ultra-high vacuum (UHV) system and has both pressure and temperature regulation systems. The microbalance had a long-term stability of $\pm 1 \mu \mathrm{g}$ with a weighing resolution of $0.2 \mu \mathrm{g}$. Activation of samples was carried out by heating to $393 \mathrm{~K}$ under vacuum $\left(<\sim 10^{-4}\right.$ mbar $)$ until desorption was complete (typically for $\sim 6-12$ hours. The pressure transducer used had range of $0-2$ MPa. Adsorption isotherms for $\mathrm{CO}_{2}$ up to 20 bar at 273-303 K were obtained using a circulating water-ethylene glycol bath to control the sample temperature. The pressure and temperature were controlled by computer using IGA software during isotherm measurements. $\mathrm{N}_{2}$ and $\mathrm{H}_{2}$ adsorption isotherms were obtained on a Quantachrome Autosorb instrument with the adsorption pressure set in a range of $0-1$ bar. $\mathrm{H}_{2}$ adsorption isotherms were obtained at two adsorption temperatures 77 (liquid nitrogen) and $87 \mathrm{~K}$ (liquid argon). Before each adsorption experiment, the sample was degassed under vacuum at $383 \mathrm{~K} . \mathrm{N}_{2}$ adsorption at 77 $\mathrm{K}$ was used to determine BET surface areas. Two optimal batches of products were compared, and the BET surface areas varied within the ranges of $410-470$ and $43-60 \mathrm{~m}^{2} \mathrm{~g}^{-1}$ for PMF-NOTT-1 and PMF-NOTT-2, respectively. For convenience, the adsorption analysis was based upon a the same batch of each PMF product. $\mathrm{CO}_{2}$ adsorption at $273 \mathrm{~K}$ was used to 
determine micropore surface areas and volumes, and non-local density function theory (NLDFT) with a slit shaped pore model was used to fit the adsorption branch of the $\mathrm{N}_{2}$ adsorption/desorption isotherm $(77 \mathrm{~K})$ to obtain pore size distributions. The $\mathrm{CO}_{2}$ adsorption isotherms were analyzed using the virial equation (1):

$$
\ln (n / P)=A_{0}+A_{1} n+A_{2} n^{2}+\cdots
$$

where $P$ is pressure $(\mathrm{Pa}), n$ is adsorption quantity $\left(\mathrm{mol} \mathrm{g}^{-1}\right)$ and $A_{n}$, are virial coefficients. At low uptakes, a graph on $\ln (n / P)$ versus $n$ is linear with gradient $A_{1}$ and intercept $A_{0} . A_{0}$ is $\exp ($ $K_{H}$ ), where $\mathrm{K}_{\mathrm{H}}$ is the Henry's law constant. The isosteric adsorption heat at zero coverage is expressed as

$$
q^{s t, 0}=R \frac{\partial A_{0}}{\partial(1 / T)}
$$

where $R$ is gas constant $\left(8.314 \mathrm{~J} \mathrm{~K}^{-1} \mathrm{~mol}^{-1}\right)$ and $T$ is the adsorption temperature $(\mathrm{K})$. A graph of $A_{0}$ versus $1 / T$ has a gradient of $q^{s t, 0} / R$ and this was used to calculate $q^{s t, 0}$.

\section{Knoevenagel Condensation Reactions using PMFs as Organocatalysts}

A $50 \mathrm{~mL}$ round-bottomed flask was charged with catalyst $(20 \mathrm{mg})$ in toluene $(4 \mathrm{~mL})$, aldehyde $(1 \mathrm{mmol})$ and malononitrile $(1 \mathrm{mmol})$. The reaction mixture was stirred at $110^{\circ} \mathrm{C}$ for $\sim 55$ hours. The reaction was monitored periodically by analyzing the sample using a Hewlett Packard 5890 series II gas chromatograph (GC) with FID detector and high purity He as the carrier gas. The products were identified by gas chromatography-mass spectrometry (GCMS) using a Hewlett Packard 6890 series spectrometer and by comparison with pure authentic commercial samples. The yields of the product were determined by using nitrobenzene as the external standard considering the response factors as unity. The mass balances of the recovered reaction mixture accounted for more than $96 \%$ of the initial substrate. After the catalytic reaction, the catalyst was recovered by filtration, washed in acetonitrile and dried under air at room temperature. The recovered catalyst was used for the 
next run with fresh aldehyde and malonitrile. The percentage conversion, purity and relative yields of the final products were determined.

\section{Results and Discussion}

\section{Determination of PMF structures and solvent and thermal stabilities}

The synthesis of PMF-NOTT-1 and PMF-NOTT-2 requires only relatively mild reaction conditions involving glacial acetic acid at $120^{\circ} \mathrm{C}$ rather than complex metal catalysts as required, for example, for the synthesis of poly(aryleneethynylene) via Pd-catalyzed Sonogashira-Hagihara cross coupling ${ }^{20}$ or of polycarbazoles via $\mathrm{FeCl}_{3}$ catalyzed oxidative coupling. ${ }^{21}$ In comparison, the adopted synthetic route described herein is much simpler and therefore, potentially cheaper for scaling up. The PMF materials show high chemical stability for use as catalysts in synthetic environments and adsorption in aqueous systems. The yellow solid PMF powder products obtained are insoluble in common solvents such as $n$-hexane, toluene, $\mathrm{CH}_{2} \mathrm{Cl}_{2}$, tetrahydrofuran (THF), $\mathrm{CHCl}_{3}$, ethyl acetate, methanol, acetonitrile, dimethylformamide (DMF) and dimethyl sulfoxide (DMSO), acids (2 - $6 \mathrm{M}$ of $\mathrm{H}_{2} \mathrm{SO}_{4}$, $\mathrm{HNO}_{3}$ and $\left.\mathrm{HCl}\right)$ and bases $(2-6 \mathrm{M}$ of $\mathrm{NaOH}$ and $\mathrm{KOH})$ at ambient temperature, and are generally chemically robust. The following catalytic reactions operated at $110^{\circ} \mathrm{C}$ in toluene also indicated the relative stability of these PMF materials. Such resistance toward solvents and acids/bases has been observed for other nanoporous covalent organic frameworks (COFs) such as conjugated microporous polymers $(\mathrm{CMP}-1 \sim 4)^{20}$ and porous polymer networks (PPN$1 \sim 5)^{22,23}$ fabricated through various coupling reactions. As potential catalysts, it is crucial that the PMFs have high chemical stability in various media without reduction in catalytic activity. This property distinguishes PMFs from many MOFs materials, which, although having unique microporous structures, can be unstable in aqueous solution or in humid gas, thus incurring extra expense in drying the feed stream before contacting with MOFs. 
The core structures of PMF-NOTT-1 and PMF-NOTT-2 were identified by IR and solidstate ${ }^{13} \mathrm{C}$ NMR spectroscopies. ${ }^{13} \mathrm{C}$ CPMAS NMR spectra at the MAS rate $17 \mathrm{kHz}$ demonstrate (Figure 1) the similarity between the structures of the two compounds. The intense peaks between 140 and 127 ppm are assigned to the aromatic carbon centers, except for the quaternary carbon 5 , which contributes to the resolved shoulder at $148 \mathrm{ppm}$, along with carbon 4 . The weaker peaks at 118, 84 and 43 ppm correspond to - $\mathrm{CN}$ (carbon 3), $\mathrm{C}=\mathrm{C}-\quad$ (carbon 2) and the aliphatic carbon on the dihydropyridyl group (carbon 1), respectively. The presence of the latter resonance confirms that the structure retains a dihydropyridyl ring, rather than the aromatic pyridyl alternative. IR spectra show (Figure 2) sharp intense peaks at $\sim 2204 \mathrm{~cm}^{-1}$ characteristic of a $v(\mathrm{C} \equiv \mathrm{N})$ stretching vibration. These results confirm that the PMFs have extended networks with a core structure analogous to molecule 3. The functionalities (-CN and $-\mathrm{NH}-)$ not only affect the conjugated system of PMFs, but also provide opportunities for further functionalization of materials. These functionalities endow the PMFs with specific catalytic activity. Powder X-ray diffraction profiles for PMF-NOTT-1 and PMF-NOTT-2 do not show any significant peaks confirming that the PMF structures are amorphous. Irregular cross-linking and disordered interpenetration might exist in the polymer structures, in particular, for PMF-NOTT-2 which is constructed from long building molecular struts. The lack of information about the long range order or connectivity of molecular building blocks makes structural modeling problematic. This is a wide spread problem for this type of polymer material. Elemental analysis shows discrepencies between the experimental and calculated values based on ideal PMF structures. Similar differences have been reported previously for porous organic polymers, for example CMP-0 $2,{ }^{24}$ pp-CMP ${ }^{25} \mathrm{COF}-1 \sim 5^{4}$ and TFPT-COF. ${ }^{26}$ For both PMFNOTT-1 and PMF-NOTT-2, the experimentally determined carbon content is higher and nitrogen analysis is lower than expected. Therefore, it is possible that a higher proportion of 
phenyl groups may be present in PMF structures than expected due to a small amount of unreacted phenyl aldehyde compound 5. Only one aldehyde group participates in cyclisation reaction to form a dihydropyridine node, and minor amounts of these substructures may influence the PMF analysis, structure, adsorption characteristics and catalytic properties. Purification and recrystallization of these materials is further inhibited by their insolubility in common solvents.

The thermal stability of PMFs has been assessed by the thermogravimetric analysis (TGA) which confirms that both are thermally stable up to $400^{\circ} \mathrm{C}$ (Figure 3). Importantly, IR spectra of the heat-treated samples $\left(400^{\circ} \mathrm{C}\right.$ for 30 minutes $)$ confirm that the cyano groups remain intact. Above this temperature, the PMFs are gradually carbonized, but without such rapid decomposition as often found with carboxylate metal organic frameworks (MOFs). ${ }^{27}$ The TGA analyses confirmed that the PMF-NOTT-1 has weight losses of 11.2 and $14.7 \mathrm{wt} \%$ at 100 and $400^{\circ} \mathrm{C}$, respectively. The corresponding values for PMF-NOTT-2, were 6.8 and 7.9 $\mathrm{wt} \%$. Most of the water adsorbed in PMFs is released at low temperatures below $\sim 100^{\circ} \mathrm{C}$, and the amounts of water released in the thermogravimetric studies of PMF-NOTT-1 and PMFNOTT-2 are, to some extent, related to the porosity of PMFs.

\section{Halochromic property of PMFs}

These chemically robust PMF solids are responsive to changes in solution $\mathrm{pH}$, reversibly switching color between yellow and red at low and high $\mathrm{pH}$, respectively (Figure 4). Such notable halochromism is attributed to the dihydropyridine moieties embedded in the framework. The reversible deprotonation and protonation of dihydropyridines exerts a significant impact on electron delocalization in this amine-functionalized conjugated system, as revealed by changes in UV-Vis absorption spectra (Figure S3). The protonated forms of the PMFs show broad absorption below $420 \mathrm{~nm}$ resulting in yellow solids. In alkaline solution, the PMFs are deprotonated and the broad absorption bands shift significantly to 
lower energies with the polymers changing to red in color. These shifts in absorption to longer wavelength and lower energy are consistent with an extension of the conjugated $\pi$ system resulting in a decrease in HOMO-LUMO energy gap. Conversely, lowering the $\mathrm{pH}$ acts as a "switch off" function by protonating the pyridine moiety and reducing the conjugated $\pi$ system. Therefore, these solvent-insoluble halochromic PMF solid particles change color reversibly and have potential as specific $\mathrm{pH}$ indicators or specific dyes with a characteristic switching ability.

\section{Characterization of Porosity}

Both PMFs have extensive porous structures and adsorb $\mathrm{N}_{2}$ and $\mathrm{CO}_{2}$. PMF-NOTT-1 has a much higher BET surface area $\left(\sim 414 \mathrm{~m}^{2} \mathrm{~g}^{-1}\right)$ than PMF-NOTT-2 $\left(\sim 60 \mathrm{~m}^{2} \mathrm{~g}^{-1}\right)$ as determined by $\mathrm{N}_{2}$ adsorption at $77 \mathrm{~K}$ (Figure $\mathrm{S} 4$ ) revealing a high concentration of accessible micropores in PMF-NOTT-1. This contrasts with the $\mathrm{CO}_{2}$ adsorption data discussed later, which shows that the isotherms and micropore volumes for PMF-NOTT-1 and PMF-NOTT-2 are very similar (Figures 5 and S6). The relatively low value of the BET surface area for PMF-NOTT2 is ascribed to $\mathrm{N}_{2}$ activated diffusion in very narrow ultramicroporosity possibly formed by the irregular cross-links and disordered interpenetration within the structure. Non-local density functional theory (NLDFT) analysis confirms the existence of two types of pores in both PMF-NOTT-1 in the ranges of $\sim<1.7 \mathrm{~nm}$ and $\sim 2.5-5.0 \mathrm{~nm}$, corresponding to micropores and mesopores, respectively (Figure S5). The activated diffusion effects in PMFNOTT-2 lead to the contribution from the narrowest porosity being reduced in the pore size distribution. The presence of mesoporosity is thought to be responsible for the characteristic hysteresis observed in both the $\mathrm{N}_{2}$ and $\mathrm{CO}_{2}$ isotherms, and indeed mesoporosity facilitate rapid transport during adsorption and catalysis.

The type I isotherms observed for $\mathrm{CO}_{2}$ adsorption (Figure 5) up to 20 bar at $273 \mathrm{~K}$ confirm uptakes of $\sim 28.4$ and $28.9 \mathrm{wt} \%$ at 20 bar $\left(\sim 6.5 \mathrm{mmol} \mathrm{g}^{-1}\right.$ at $\left.p / p^{0} \sim 0.57\right)$ for PMF-NOTT-1 
and PMF-NOTT-2, respectively. The Dubinin-Radushkevich (D-R) plots (Figure S6) are linear for the low relative pressure range and deviate upwards at higher relative pressures. This indicates the presence of larger pores sizes as shown in the pore size distribution obtained from $\mathrm{N}_{2}$ adsorption at $77 \mathrm{~K}$ (Figure S5). Extrapolation of the linear region to give the intercept at $\ln ^{2}\left(p / p^{0}\right)=0$ provides the amount adsorbed corresponding to the D-R micropore volume. The D-R micropore volumes for $\mathrm{CO}_{2}$ adsorption isotherm data at $273 \mathrm{~K}$ were measured as $\sim 0.142 \pm 0.001$ and $0.144 \pm 0.001 \mathrm{~cm}^{3} \mathrm{~g}^{-1}$ assuming a $\mathrm{CO}_{2}$ density of $1.032 \mathrm{~g} \mathrm{~cm}^{-3}$ for PMF-NOTT-1 and PMF-NOTT-2, respectively. The $\mathrm{CO}_{2}$ micropore volumes for both materials corresponds to a surface area of $\sim 380 \mathrm{~m}^{2} \mathrm{~g}^{-1}$ (assuming area of $\mathrm{CO}_{2}$ molecule $\left.=1.9 \times 10^{-19} \mathrm{~m}^{2}\right)$. This is similar to the $\mathrm{N}_{2}(77 \mathrm{~K})$ BET surface area $\left(414 \mathrm{~m}^{2} \mathrm{~g}^{-}\right.$ ${ }^{1}$ ) for PMF-NOTT-1. It also confirms that both PMFs have similar micropore volumes and surface areas accessible to $\mathrm{CO}_{2}$ at temperatures of $273 \mathrm{~K}$ and above. The Langmuir plots for $\mathrm{CO}_{2}$ adsorption at $273 \mathrm{~K}$ were linear $(\mathrm{R}>0.998)$ in the region $10-20$ bar and extrapolation to the saturated vapor pressure (34.92 bar) give uptakes of $7.79 \pm 0.33$ and $7.90 \pm 0.31 \mathrm{mmol} \mathrm{g}^{-1}$ for PMF-NOTT-1 and PMF-NOTT-2, respectively. These values are not significantly different and correspond to total pore volumes of $0.332 \pm 0.014$ and $0.337 \pm 0.013 \mathrm{~cm}^{3} \mathrm{~g}^{-1}$ for PMF-NOTT-1 and PMF-NOTT-2, respectively. The $\mathrm{N}_{2}$ adsorption data at $77 \mathrm{~K}$ gave total pore volumes of $0.385 \mathrm{~cm}^{3} \mathrm{~g}^{-1}$ for PMF-NOTT-1 and $0.042 \mathrm{~cm}^{3} \mathrm{~g}^{-1}$ for PMF-NOTT-2 (at $p / p^{0}$ $=0.995$, assuming liquid $\mathrm{N}_{2}$ density $\left.0.808 \mathrm{~g} \mathrm{~cm}^{-3}\right)$. The total pore volumes from $\mathrm{N}_{2}(77 \mathrm{~K})$ and $\mathrm{CO}_{2}(273 \mathrm{~K})$ are comparable for PMF-NOTT-1. The lower $\mathrm{N}_{2}$ total pore volume and surface area values for PMF-NOTT-2 can be attributed to activated diffusion effects through very narrow constrictions in the porosity, which is the critical rate determining process at 77 K.

In terms of the pore size distributions, the D-R plots are an indication of available adsorption volume being filled beyond that predicted by the Gaussian micropore distribution 
function used in the derivation of the D-R equation. This "additional" adsorption capacity could be due to (a) filling of supermicroporosity, (b) filling of mesoporosity or (c) multilayer formation. In the case of the materials described herein, mesopores are being filled. Other investigations have confirmed that adsorption in polymers of intrinsic microporosity (PIMs) and conjugated microporous polymers (CMPs) may involve potential network swelling and hysteretic adsorption. ${ }^{12-16,28}$

The $\mathrm{CO}_{2}$ isotherms can be described by virial equation (1). The values of $A_{l}$ for both materials were similar for fitting the isotherm data to a two-parameter linear virial equation at low uptake and a three-parameter virial equation for the complete isotherm data (Figure S7). The values of $A_{l}$ from the linear virial plots for $273-303 \mathrm{~K}$ lay in the range -972 to $-1179 \mathrm{~g}$ $\mathrm{mol}^{-1}$ and -855 to $-1057 \mathrm{~g} \mathrm{~mol}^{-1}$ for PMF-NOTT-1 and PMF-NOTT-2, respectively, and describe the $\mathrm{CO}_{2}-\mathrm{CO}_{2}$ interactions (Figure S7). These values are very similar to the values of $A_{l}$ (-1000 to $-1045 \mathrm{~g} \mathrm{~mol}^{-1}$ for $303-343 \mathrm{~K}$ ) observed for $\mathrm{CO}_{2}$ adsorption on carbon molecular sieve (CMS) material used for air separation by pressure swing adsorption. ${ }^{29}$ The CMS material was prepared by carbon deposition on an ultramicroporous carbon substrate to provide kinetic selectivity for molecular sieving of oxygen and nitrogen. ${ }^{29-31}$

The values of $A_{0}$ for PMF-NOTT-1 and PMF-NOTT-2 were used to determine the isosteric adsorption heats at zero coverage $\left(q^{s t, 0}\right)$ from equation (2), which is a fundamental measure of the $\mathrm{CO}_{2}$-surface interactions. These values were found to be $33.1 \pm 3.3$ and $31.9 \pm 1.4 \mathrm{~kJ} \mathrm{~mol}^{-}$ 1, for PMF-NOTT-1 and PMF-NOTT-2, respectively, suggesting that both materials have similar surface interactions with $\mathrm{CO}_{2}$ (Figure S7 and S8). These $q^{\text {st, } 0}$ values are comparable to those of porous $\mathrm{COF}$ materials rich in $\mathrm{CO}_{2}$-binding moieties such as $-\mathrm{N}=\mathrm{N}-,-\mathrm{COOH}$ and $\mathrm{SO}_{3} \mathrm{H}$ moieties, for example, azo-COP-1-3 ( $\left.32.1 \mathrm{~kJ} \mathrm{~mol}^{-1}\right),{ }^{32} \mathrm{CMP}-1-\mathrm{COOH}\left(\sim 32.6 \mathrm{~kJ} \mathrm{~mol}^{-}\right.$ $\left.{ }^{1}\right)^{33}$ and $\mathrm{PPN}-6-\mathrm{SO}_{3} \mathrm{H} / \mathrm{SO}_{3} \mathrm{Li}\left(30.0-35.0 \mathrm{~kJ} \mathrm{~mol}^{-1}\right){ }^{34}$ These values are higher than those observed for materials without polar functionalities and carbon molecular sieves $(28.4 \pm 0.7$ 
$\left.\mathrm{kJ} \mathrm{mol}^{-1}\right) .{ }^{29}$ A wide range of $q^{\text {st, },}$ values have been obtained for $\mathrm{CO}_{2}$ binding in MOFs ranging from 20 - $\left.96 \mathrm{~kJ} \mathrm{~mol}^{-1}\right)^{35}$ with [CuBTTri] $\left(\mathrm{H}_{3} \mathrm{BTTri}=1,3,5\right.$-tri( $1 H$-1,2,3-triazol-4-yl)benzene $\left.)\right)$ incorporating $\mathrm{N}, \mathrm{N}$-dimethylethylenediamine (mmen) groups exhibiting one of the highest values of $q^{\text {st, } 0}$ of $96 \mathrm{~kJ} \mathrm{~mol}^{-1} .^{36}$ The isosteric heat of adsorption decreases with increasing surface coverage (Figure S9). This trend is different from that observed interpenetrated MOF NOTT-202a, where there is an initial decrease followed by an increase in heat of adsorption. ${ }^{37}$ The difference in the trends is attributed to framework flexibility in the latter. Recently, Xie et al used the organic polymer materials loaded with cobalt based heterogeneous catalysts to adsorb $\mathrm{CO}_{2}$ and then convert propylene oxide into propylene carbonate at atmospheric pressure and room temperature. ${ }^{38}$

$\mathrm{H}_{2}$ adsorption isotherms for both PMFs are reversible with an adsorption capacity of $\sim 0.8$ wt $\%$ at $0.1 \mathrm{MPa}$ at $77 \mathrm{~K}$ (Figure S10), which is similar to that of nanoporous polyanilines, ${ }^{24}$ but lower than the porous poly(aryleneethynylene) (PAE) polymers. ${ }^{24}$ Both PMFs show isosteric heats of adsorption $q^{\text {st, } 0}$ at zero coverage for $\mathrm{H}_{2}$ uptake of about $8.9-9.5 \mathrm{~kJ} \mathrm{~mol}^{-1}$ (Figure S11) which is comparable to those values of the CMP polymers (CMP-0-5: 10.0 kJ $\mathrm{mol}^{-1}$ ) but higher than the hypercross-linked polystyrene polymers ${ }^{40}$ and most MOFs that do not contain unsaturated metal centers $\left(4.0-7.0 \mathrm{~kJ} \mathrm{~mol}^{-1}\right){ }^{41-44}$ In addition to the microporous structure providing strong overlap potentials, the diverse polar functionalities in these materials, most notably $\mathrm{N}-\mathrm{H}$ and $\mathrm{CN}$ groups, may increase host-guest surface interactions.

\section{Catalytic Studies}

The catalytic performances of PMF-NOTT-1 and PMF-NOTT-2 were assessed in Knoevenagel condensation reactions (Figure 6). Both materials show high selectivity (typically 98\%) confirming good catalytic specificity with little by-product formation. The lower conversion using PMF-NOTT-2 is ascribed to restrictions imposed on reactants 
entering micropores where active sites are concentrated, as discussed above. A similar case has been observed by Kitagawa et $a .^{45}$ in a MOF, where amide groups, which act as weak base active sites, are arranged facing the open channels. The reduction of porosity in the desolvated MOF is proposed to restrict the interaction of larger substrates with sites inside channels, resulting in lower conversion. ${ }^{45}$ Notably, at the same selectivity of $\sim 98 \%$, incorporation of $-\mathrm{CH}_{3}$ groups into the aldehyde substrate leads to conversions of $\sim 93 \%$, significantly higher than for $-\mathrm{Cl}$ and $-\mathrm{CN}$ derivatives, which are converted in $64 \%$ and $54 \%$ yields, respectively (Figure 6 and Table S1). The influence of the $-\mathrm{CH}_{3}$ group on increasing - $\mathrm{CHO}$ activity is against the general reactivity of carbonyl groups in condensation reactions based solely on electronic effects ${ }^{46-48}$ and probably derives from the higher activity of PMFNOTT catalysts for these substrates, most likely by preferential adsorption and higher affinity for $p$-tolualdehyde with respect to $-\mathrm{Cl}$ or $-\mathrm{CN}$ substituted benzaldehydes.

The catalytic stability and activity of PMF-NOTT-1 were specifically tested in the conversion of benzaldehyde to benzylidenepropanedinitrile. On removal of the catalyst by filtrations at $15 \%$ conversion during the reaction with benzaldehyde, no further reaction was observed with conversion stabilizing at $\sim 15-18 \%$ (Figure 7 ). This provides direct evidence of the stability of the active sites within PMF-NOTT-1, indicating that they are stable and not leached out into solution during reaction. The reusability of PMF-NOTT-1 was also tested (Figure 8). After each reaction run, the catalyst was removed by filtration, washed twice with acetonitrile, dried at room temperature and then reused for another catalytic run. The reproducibility of benzaldehyde conversion vs time indicates that PMF-NOTT-1 has excellent chemical stability, and importantly, it can be regenerated by filtration followed by acetonitrile washing and drying in a convenient manner at least three times without significant loss of catalytic activity. This is an advantage over other analogous polymeric catalysts, such as bifunctional polystyrene bearing 4-dimethylaminopyridine (DMAP) and 
piperidine as active components, ${ }^{49}$ which are effective as catalysts in decarboxylative Doebner-Knoevenagel condensation reactions, but are soluble in product mixtures and cannot be recovered for re-use.

\section{Conclusions}

A new strategy has been developed for the design and preparation of porous macromolecular frameworks with high chemical stability. The gas adsorption characteristics of these PMF materials confirm the presence of extensive accessible porous structures. The framework functionalities have been characterized by spectroscopic methods. The dihydropyridyl moieties in the framework structure may undergo reversible protonation/deprotonation and this results in intense halochromic characteristics. The resultant materials exhibit catalytic activity towards Knoevenagel condensation reactions, their primary advantages being that they can be recovered for re-use without significant loss of catalytic activity and show reversible color changes, which are useful for monitoring catalytic activity.

\section{Acknowledgements}

We thank EPSRC and the University of Nottingham for support. MS gratefully acknowledges receipt of an ERC Advanced Grant.

$\dagger$ Electronic Supplementary Information available: [Synthetic details, solid state NMR, IR and UV-Vis spectra, SEM, gas adsorption analysis, catalytic reaction]. See DOI: $10.1039 / \mathrm{b} 000000 \mathrm{x} /$ 


\section{References}

1. J. X. Jiang, A. I. Cooper, Top. Curr. Chem., 2010, 293, 1.

2. D. J. Tranchemontagne, J. L. Mendoza-Cortés, M. O’Keeffe, O. M. Yaghi, Chem. Soc. Rev. 2009, 38, 1257.

3. N. B. McKeown, B. Gahnem, K. J. Msayib, P. M. Budd, C. E. Tattershall, K. Mahmood, S. Tan, D. Book, H. W. Langmi, A. Walton, Angew. Chem. Int. Ed., 2006, 45, 1804.

4. A. P. Côté, A. I. Benin, N. W. Ockwig, M. O'Keeffe, A. J. Matzger, O. M. Yaghi, Science, 2005, 310, 1166.

5. S. Kitagawa, R. Kitaura, S. Noro, Angew. Chem. Int. Ed., 2004, 43, 2334.

6. J. R. Li, R. J. Kuppler, H. C. Zhou, Chem. Soc. Rev., 2009, 38, 1477.

7. L. J. Murray, M. Dincă, J. R. Long, Chem. Soc. Rev., 2009, 38, 1294.

8. X. Lin, N. R. Champness, M. Schröder, Top. Curr. Chem., 2010, 293, 35.

9. L. Ma, W. Lin, Top. Curr. Chem., 2010, 293, 175.

10. S. J. Garibay, Z. Wang, S. M. Cohen, Inorg. Chem., 2010, 49, 8086.

11. J. A. Mason, K. Sumida, Z. R. Herm, R. Krishna, J. R. Long, Energy \& Environ. Sci., $2011,4,3030$.

12. A. I. Cooper, Adv. Mat., 2009, 21, 1291.

13. C. D. Wood, B. Tan, A. Trewin, H. Niu, D. Bradshaw, M. J. Rosseinsky, Y. Z. Khimyak, N. L. Campbell, R. Kirk, E. Stöckel, A. I. Cooper, Chem. Mater., 2007, 19, 2034.

14. X. Zou, H. Ren, G. Zhu, Chem. Commun., 2013, 49, 3925.

15. T. Ben, S. Qiu, CrystEngComm, 2013, 15, 17.

16. Y. Jin, Y. Zhu, W. Zhang, CrystEngComm, 2013, 15, 1484.

17. Y. Zhang, Y. Zhang, Y. L. Sun, X. Du, J. Y. Shi, W. D. Wang, W. Wang, Chem. Eur. J., $2012,18,6328$.

18. A. Facchetti, Chem. Mater., 2011, 23, 733.

19. W. Yang, A. Greenaway, X. Lin, R. Matsuda, A. J. Blake, C. Wilson, W. Lewis, P. 
Hubberstey, S. Kitagawa, N. R. Champness, M. Schröder, J. Am. Chem. Soc., 2010, 132, 14457.

20. J. Jiang, F. Su, A. Trewin, C. D. Wood, N. L. Campbell, H. Niu, C. Dickinson, A. Y. Ganin, M. J. Rosseinsky, Y. Z. Khimyak, A. I. Cooper, Angew. Chem. Int. Ed., 2007, 46, 8574.

21. Q. Chen, M. Luo, P. Hammershøj, D. Zhou, Y. Han, B. W. Laursen, C. Yan, B. Han, J. Am. Chem. Soc., 2012, 134, 6084.

22. W. Lu, D. Yuan, D. Zhao, C. I. Schilling, O. Plietzsch, T. Muller, S. Bräse, J. Guenther, J. Blumel, R. Krishna, Z. Li and H. C. Zhou, Chem. Mater., 2010, 22, 5964.

23. D. Yuan, W. Lu , D. Zhao and H. C. Zhou, Adv. Mater. 2011, 23, 3723.

24. J. X. Jiang, F. Su, A. Trewin, C. D. Wood, H. Niu, J. T. A. Jones, Y. Z. Khimyak, A. I. Cooper, J. Am. Chem. Soc., 2008, 130, 7710.

25. L. Chen, Y. Honsho, S. Seki and D. Jiang, J. Am. Chem. Soc., 2010, 132, 6742.

26. L. Stegbauer, K. Schwinghammer and B. V. Lotsch, Chem. Sci., 2014, 5, 2789.

27. L. D. O'Neill, H. Zhang, D. Bradshaw, Mater. Chem., 2010, 20, 5720.

28. B. S. Ghanem, K. J. Msayib, N. B. McKeown, K. D. M. Harris, Z. Pan, P. M. Budd, A. Butler, J. Selbie, D. Book, A. Walton, Chem. Commun., 2007, 67.

29. C. R. Reid, K. M. Thomas, Langmuir, 1999, 15, 3206.

30. C. R. Reid, I. P. O'Koye, K. M. Thomas, Langmuir, 1998, 14, 2415.

31. C. R. Reid, K. M. Thomas, J. Phys. Chem. B, 2001, 105, 10619.

32. H. A. Patel, S. H. Je, J. Park, D. P. Chen, Y. Jung, C. T. Yavuz and A. Coskun, Nature Commun., 2013, 4,1357.

33. R. Dawson, D. J. Adams and A. I. Cooper, Chem. Sci., 2011, 2, 1173.

34. W. Lu, D. Yuan, J. Sculley, D. Zhao, R. Krishna, and H. C. Zhou, J. Am. Chem. Soc. 2011, 133, 18126. 
35. K. Sumida, D. L. Rogow, J. A. Mason, T. M. McDonald, E. D. Bloch, Z. R. Herm, T-H Bae, and J. R. Long, Chem. Rev. 2012, 112, 724.

36. T. M. McDonald, D. M. D’Alessandro, R. Krishna and J. R. Long, Chem. Sci., 2011, 2, 2022.

37. S. Yang, X. Lin, W. Lewis, M. Suyetin, E. Bichoutskaia, J. E. Parker, C. C. Tang, D. R. Allan, P. J. Rizkallah, P. Hubberstey, N. R. Champness, K. M. Thomas, A. J. Blake and M. Schröder, Nature Mater., 2012,11,710.

38. Y. Xie, T. Wang, X. Liu, K. Zou and W. Deng, Nature Commun. 2013, 4, 1960.

39. J. Germain, J. M. J. Fréchet, F. J. Svec, Mater. Chem., 2007, 17, 4989.

40. V. Davankov, M. Tsyurupa, Compr. Anal. Chem., 2011, 56, 601.

41. H. Furukawa, M. A. Miller, O. M. Yaghi, J. Mater. Chem., 2007, 17, 3197.

42. M. Latroche, S. Surblé, C. Serre, C. Mellot-Draznieks, P. L. Llewellyn, J. H. Lee, J. S. Chang, S. H. Jhung, G. Férey, Angew. Chem. Int. Ed., 2006, 45, 8227.

43. S. S. Kaye, J. R. Long, J. Am. Chem. Soc., 2005, 127, 6506.

44. Y. Yan, X. Lin, S. Yang, A. J. Blake, A. Dailly, N. R. Champness, P. Hubberstey, M. Schröder, Chem. Commun., 2009, 1025.

45. S. Hasegawa, S. Horike, R. Matsuda, S. Furukawa, K. Mochizuki, Y. Kinoshita, S. Kitagawa, J. Am. Chem. Soc., 2007, 129, 2607.

46. McMurry, J. Organic Chemistry, Brooks/Cole Publishing Company 2012.

47. Z. Ren, W. Cao, W. Tong, Synth. Comm., 2002, 32, 3475.

48. S. Wang, Z. Ren, W. Cao, W. Tong, Synth. Comm., 2001, 31, 673.

49. J. Lu, P. H. Toy, Synlett, 2011, 12, 1723. 


\section{Figures}

Scheme 1. Synthesis of (a) molecular building block 3 for SOF formation and (b) porous macromolecular frameworks $\mathbf{6}$.

Figure 1. ${ }^{13} \mathrm{C}$ CPMAS NMR spectra of PMF-NOTT-1 and PMF-NOTT-2 recorded at a Larmor frequency of $150.9 \mathrm{MHz}$ and a MAS rate of $17 \mathrm{kHz}$. Spinning sidebands are indicated by asterisks.

Figure 2. Solid-state ATR-IR spectra of PMF-NOTT-1 and PMF-NOTT-2.

Figure 3. Thermogravimetric weight loss profiles of PMF-NOTT-1 and PMF-NOTT-2.

Figure 4. Reversible responses of PMFs to $\mathrm{pH}$ changes (a,d: fresh PMF/PTFE disks; b,e: $2 \mathrm{M}$ $\mathrm{NaOH}$ treatment of a and d; c, f: $2 \mathrm{M} \mathrm{HCl}$ treatment of $\mathrm{b}$ and e).

Figure 5. Adsorption isotherms of $\mathrm{CO}_{2}$ gas on PMF-NOTT-1 and PMF-NOTT-2 (solid: adsorption; open: desorption).

Figure 6. Knoevenagel condensation reactions in toluene at $110^{\circ} \mathrm{C}$. Selectivity refers to the adduct formation. Yields can be calculated by multiplying conversion by selectivity.

Figure 7. (a) Conversion of benzaldehyde in toluene vs time using PMF-NOTT-1 as catalyst; (b) at $15 \%$ conversion (ca. $6 \mathrm{~h}$ ), the catalyst was removed by hot filtration.

Figure 8. Re-usability test of PMF-NOTT-1 for the reactions between benzaldehyde and malononitrile in toluene at $110^{\circ} \mathrm{C}$. 
Scheme 1.

(a)

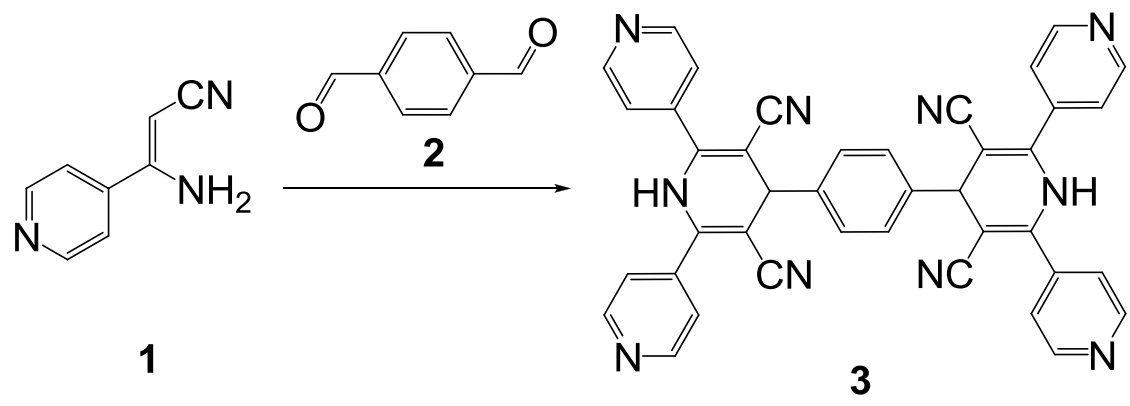

(b)
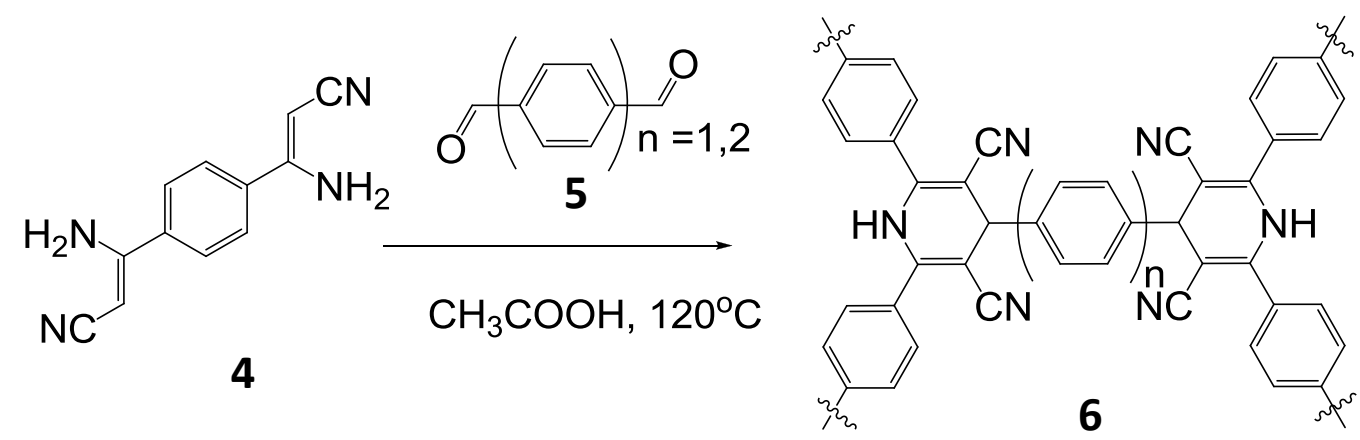

PMF-NOTT-1 $(n=1)$

PMF-NOTT-2 $(n=2)$ 
Figure 1.

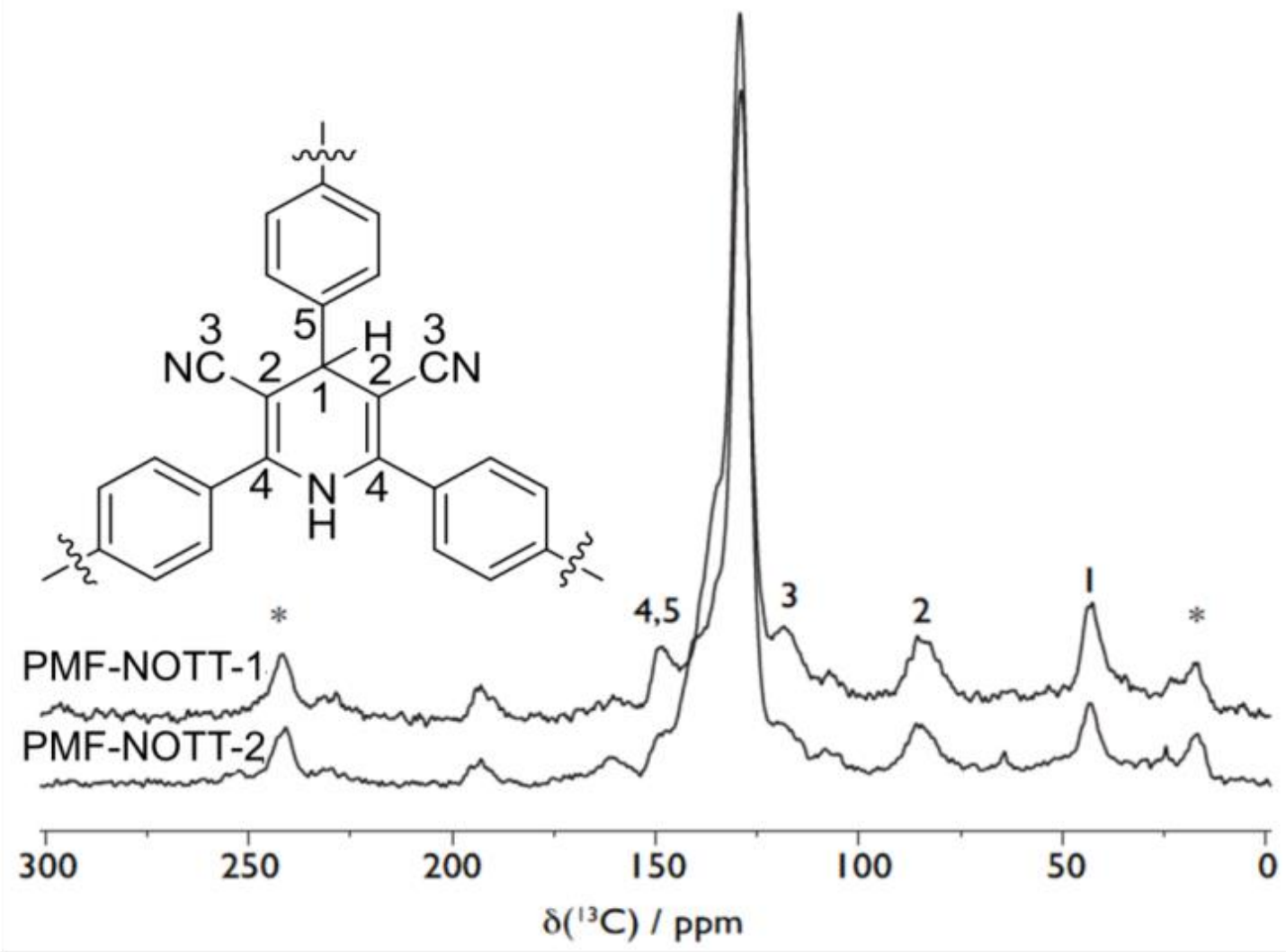


Figure 2.

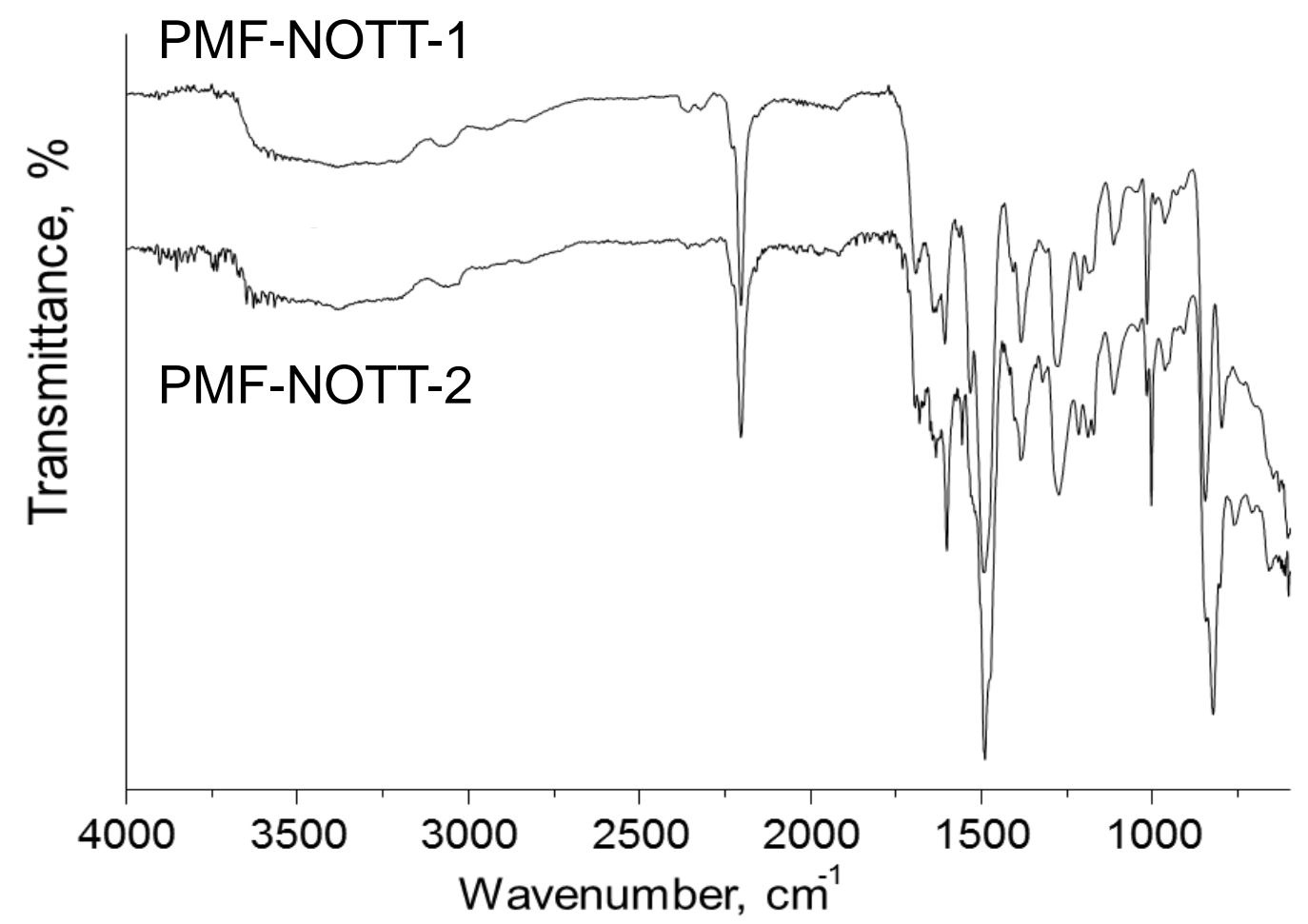


Figure 3.

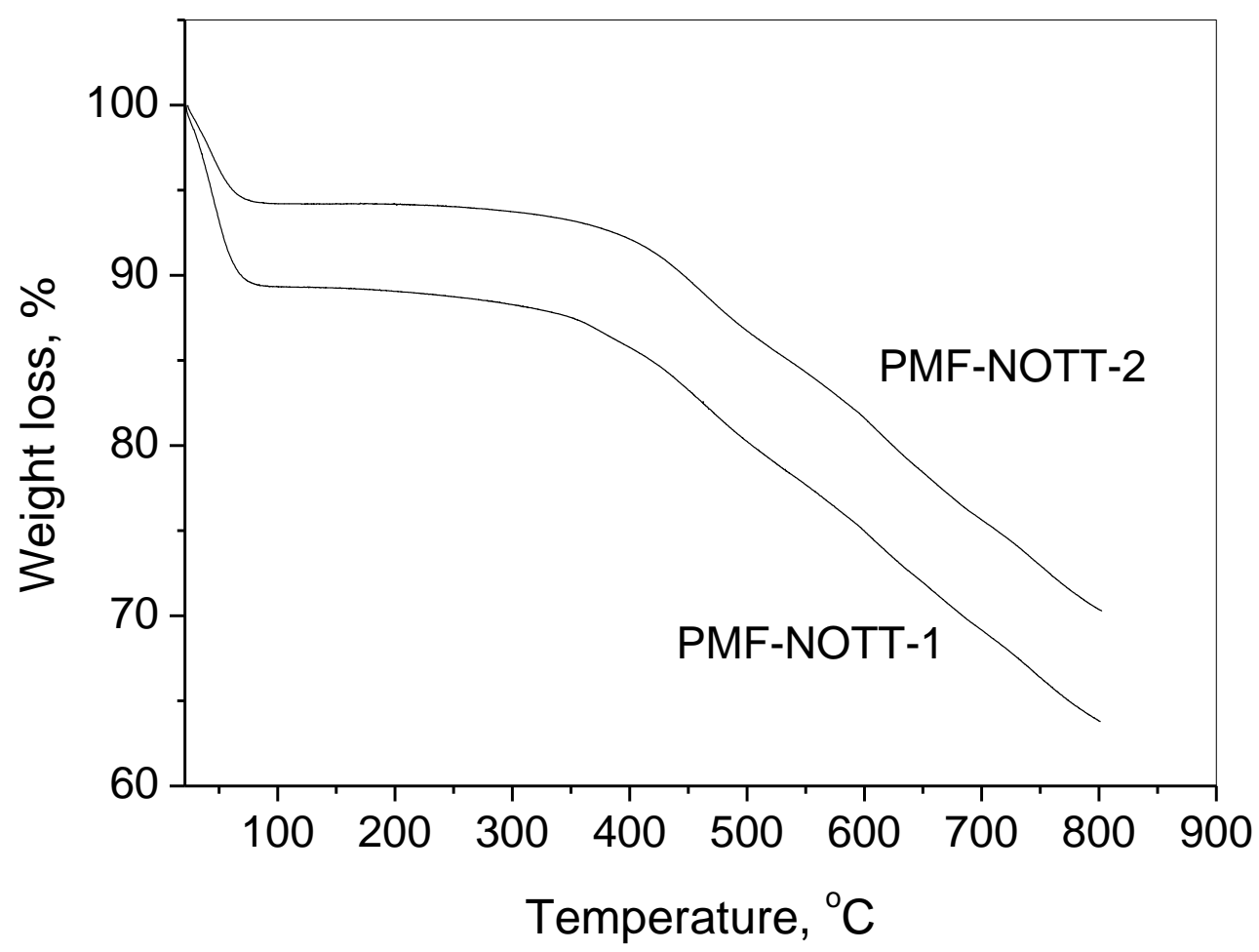


Figure 4

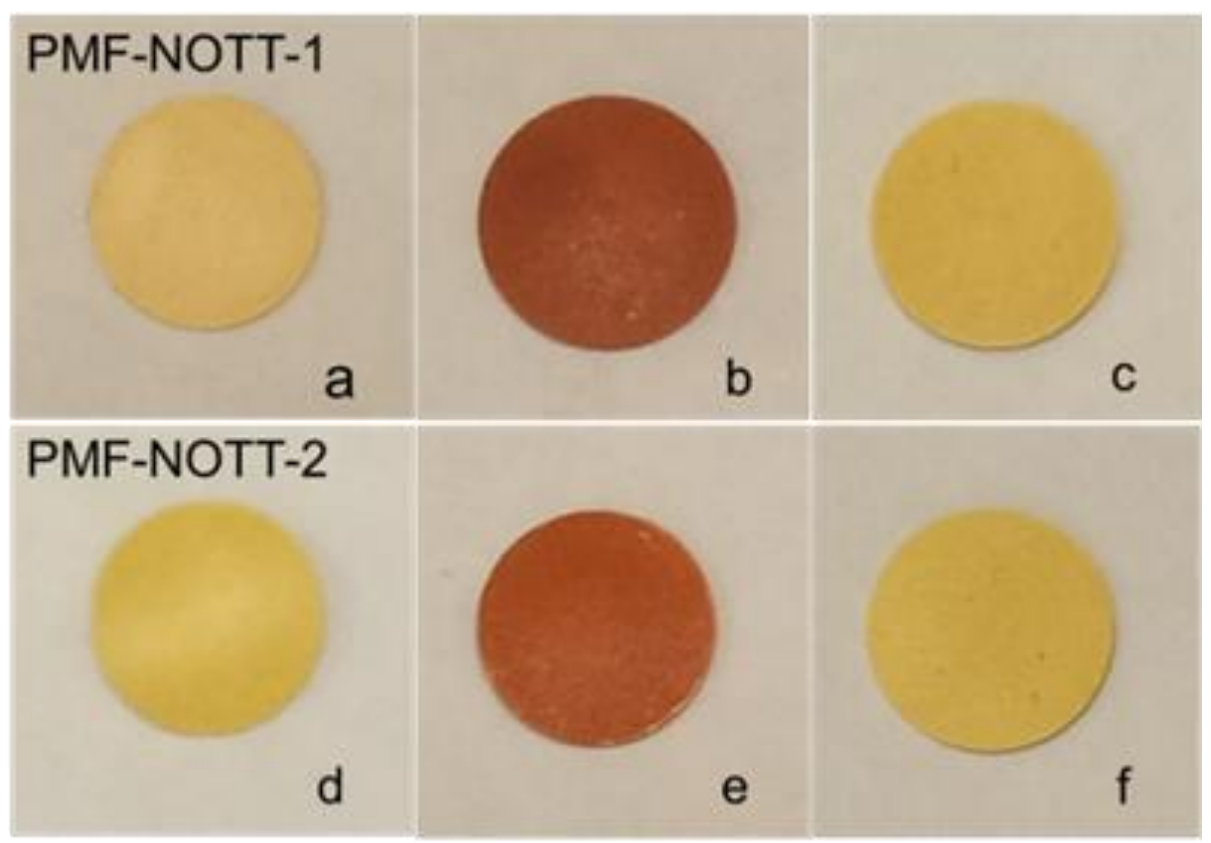


Figure 5
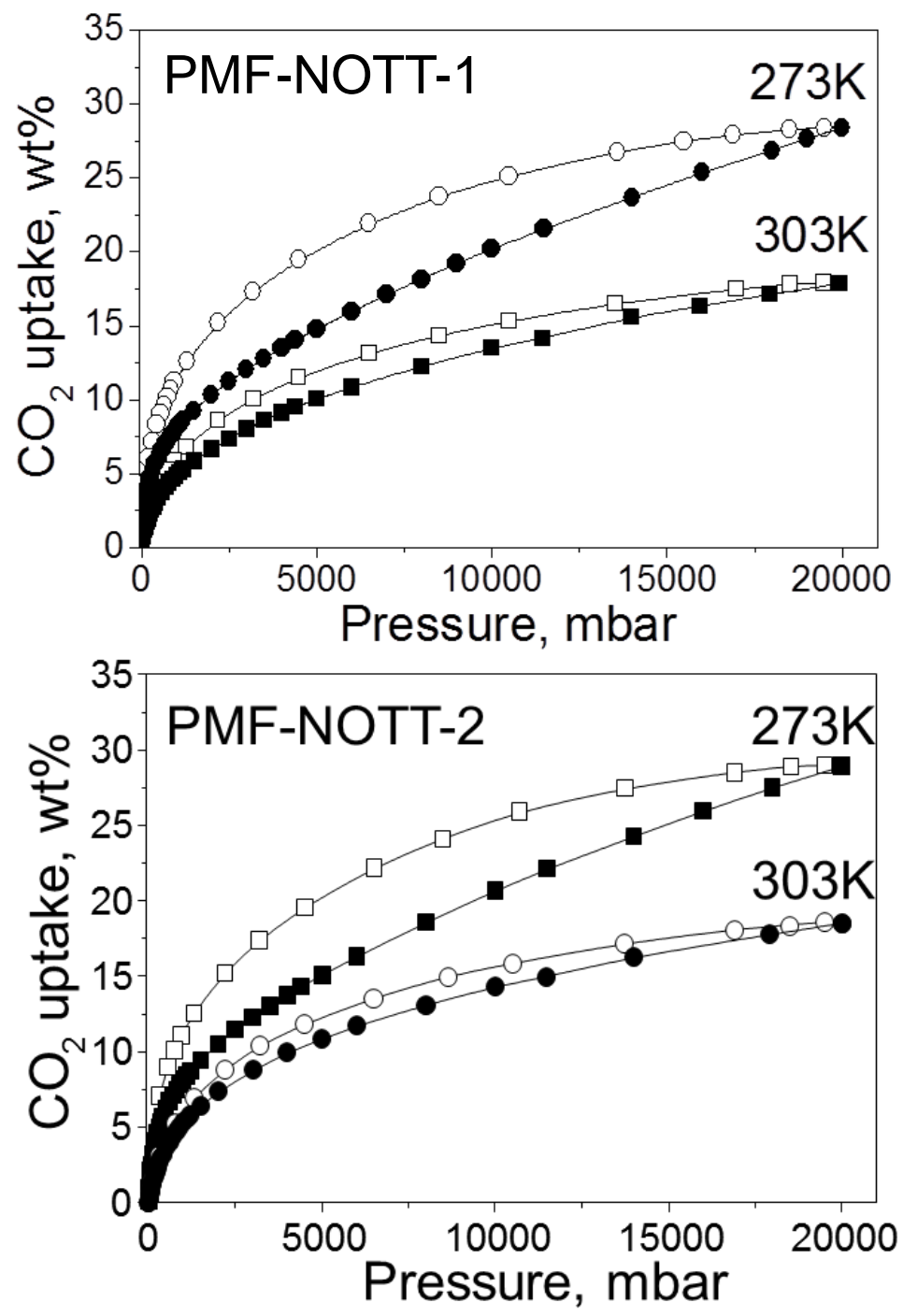
Figure 6.
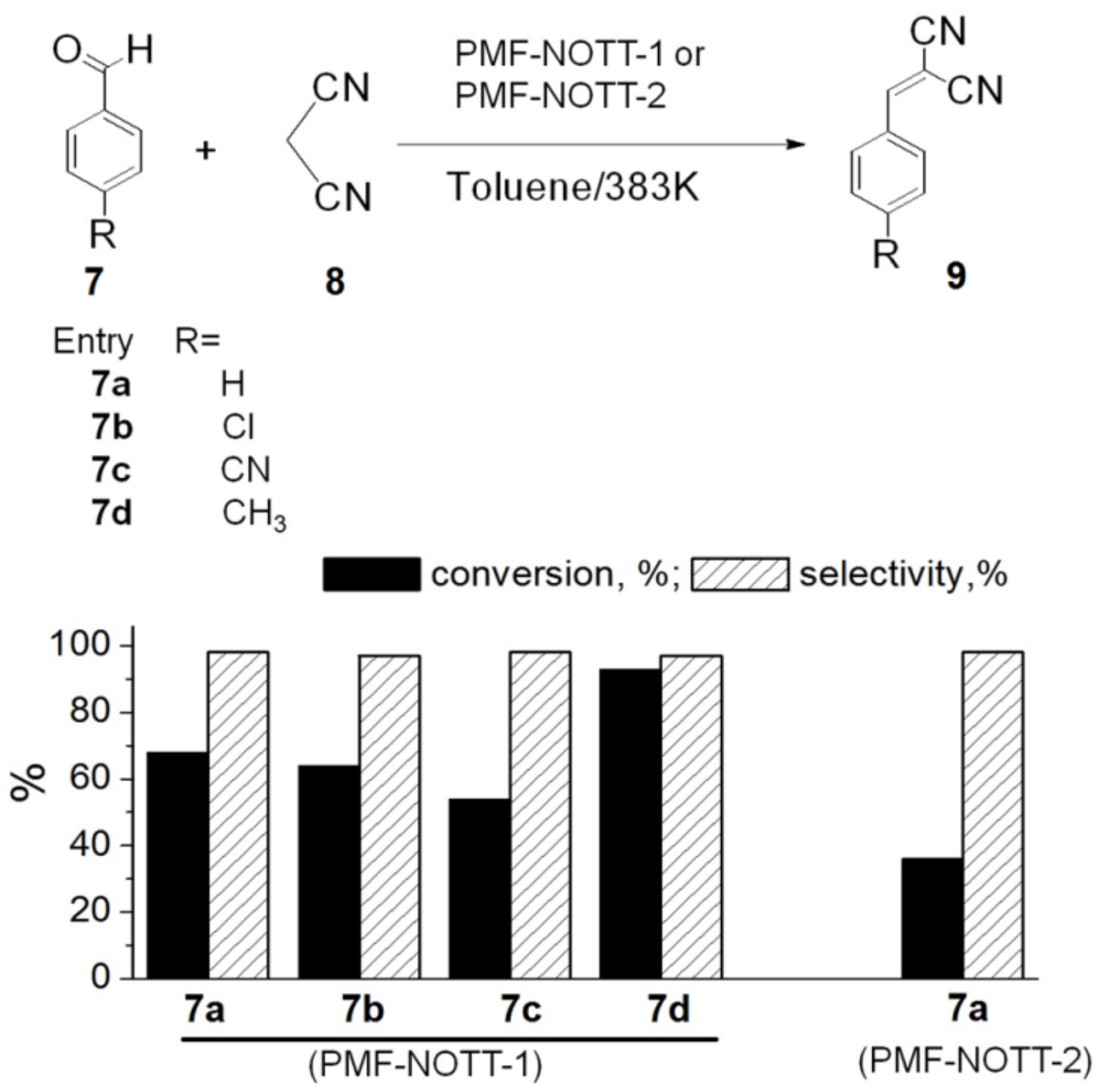
Figure 7.

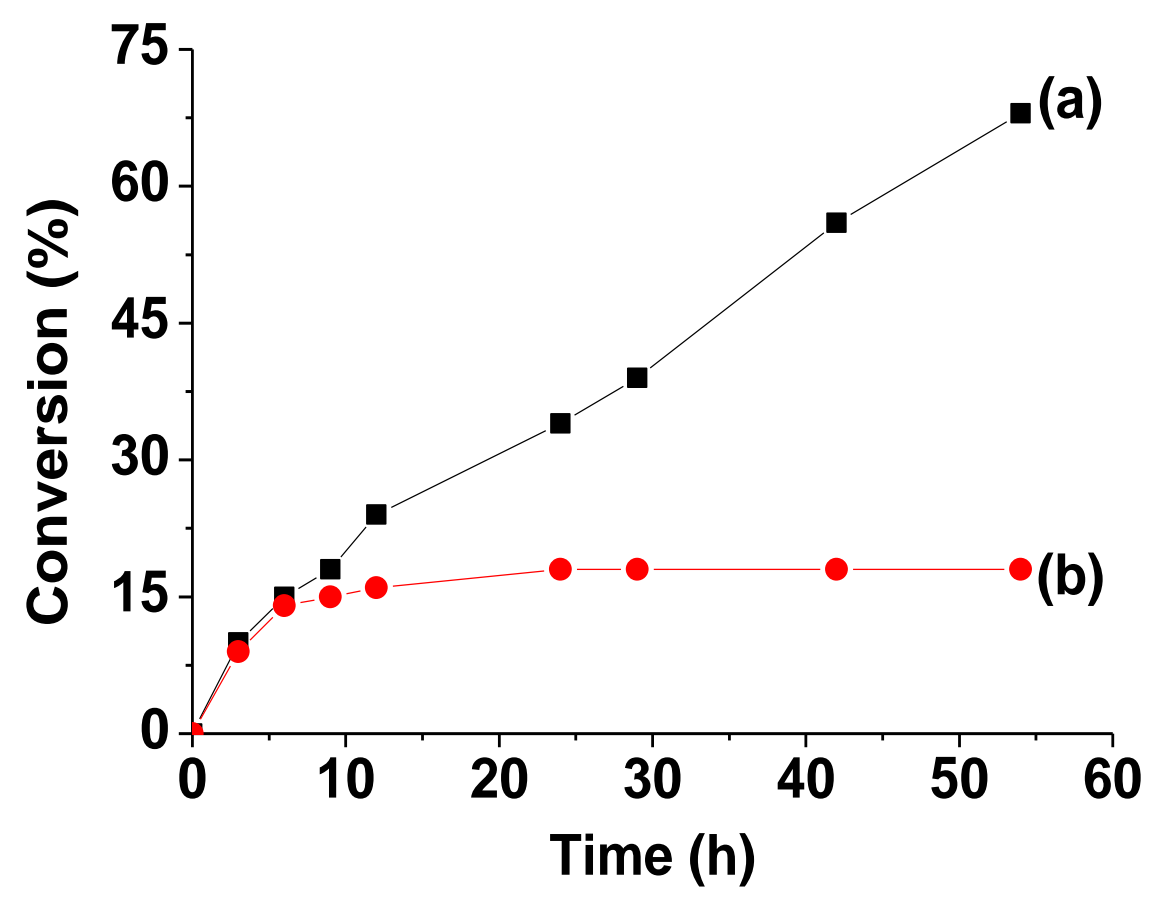


Figure 8.

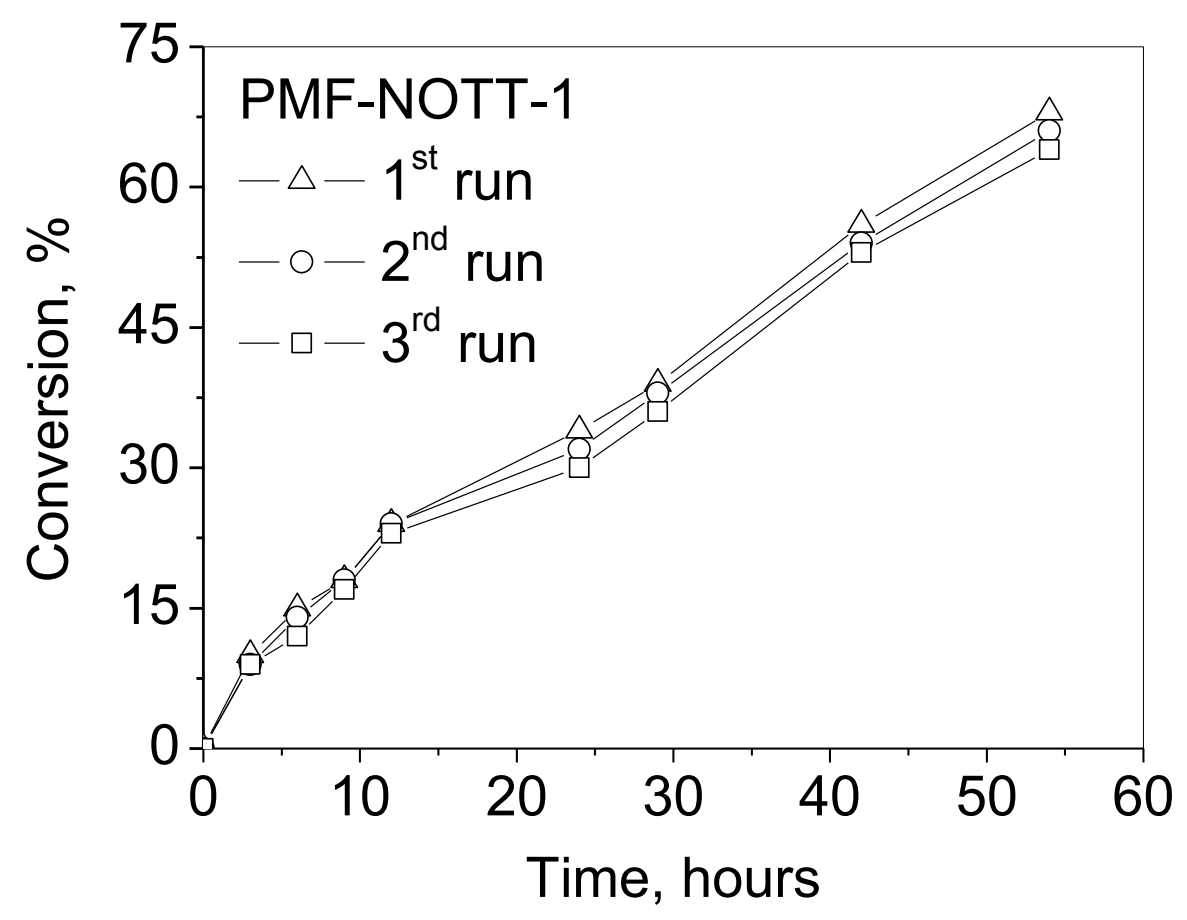

Table of Contents Graphic

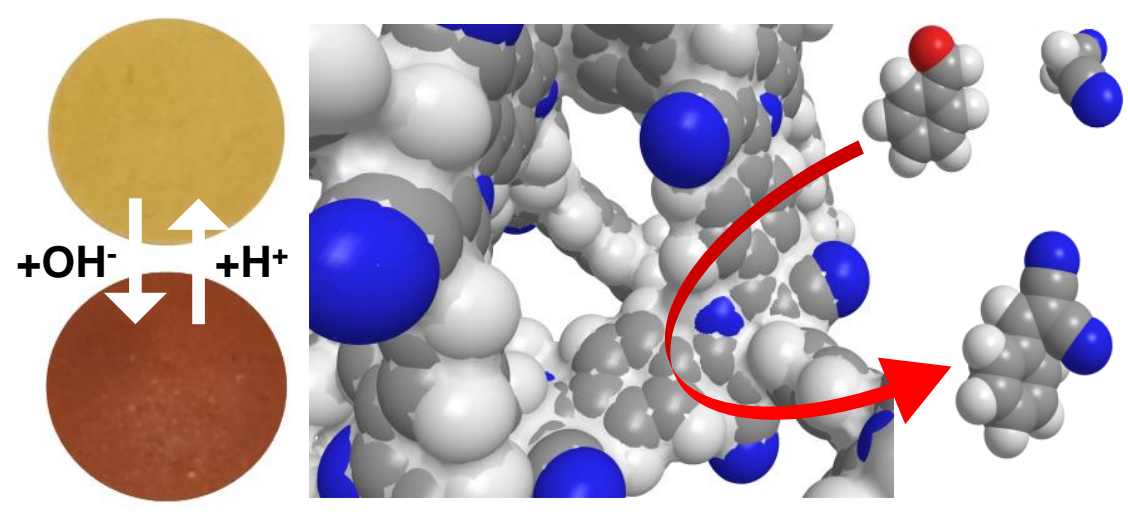


